\title{
QUIPSinfant: Pain and possible side effects in postoperative children and adolescents
}

\author{
Claudia Weinmann ${ }^{1 *}$, Marcus Komann ${ }^{1}$, Antje Götterman', Alexander Avian ${ }^{1,2}$, Winfried Meißner ${ }^{1}$ \\ From Safety in hospitals: from strategy to implementation Annual Scientific Meeting 2015 \\ Graz, Austria. 29-30 September 2015
}

\section{Background}

QUIPSinfant (QUIPSI)/PAIN OUTinfant is a web-based international registry providing clinicians with tools to carry out audits and to receive feedback of pain related outcomes in children after surgery. QUIPSI has been running since 2011 in German speaking countries. Interest in QUIPSI from healthcare providers treating children outside Germany has led to developing a version that can be implemented internationally, PAIN OUTinfant. The non-for profit project is supported by several scientific societies.

\section{Material and methods}

Children after surgery between 4 and 18 years are asked about their postoperative pain therapy and possible side effects. Pain assessment is done from the patient's point of view, using the validated, Faces Pain Scale - revised by Hicks et al. [1] and a standardized instruction on how to use it. As a valid data collection is of high priority a detailed training course and written guidelines on the standard operating procedures are provided.

\section{Results}

The QUIPSinfant registry includes 6043 children and adolescent. Forty one percent were female $(\mathrm{n}=2458)$. The mean age of all children and adolescent was $10.2 \pm$ 4.0 (f: $10.7 \pm 4.0 \mathrm{~m}: 9.9 \pm 4.0$ ). Median duration of surgery was 42 min (IQR: $24-80$ min, f: median 45 , IQR 25 - 90; m: median 40, IQR 23 - 73). About half of the children and adolescents reported no pain at all (52.8\%) and $15.3 \%$ reported clinically relevant pain (pain $\geq 4$ ) (Figure 1). Also about half of the children and

\footnotetext{
* Correspondence: Claudia.weinmann@med.uni-jena.de 'Department of Anesthesiology and Intensive Care, Jena University Hospital, Jena - Lobeda, Germany

Full list of author information is available at the end of the article
}

adolescent reported tiredness during the day (52.6\%), $24.2 \%$ reported nausea and $17.1 \%$ vomiting.

\section{Conclusions}

Despite improvements in pain management in recent years a significant number of postoperative children and adolescent still suffer from pain and possible side effects. Therefore, in hospitals a standardized assessment of pain and possible side effects is necessary to identify areas of improvement.

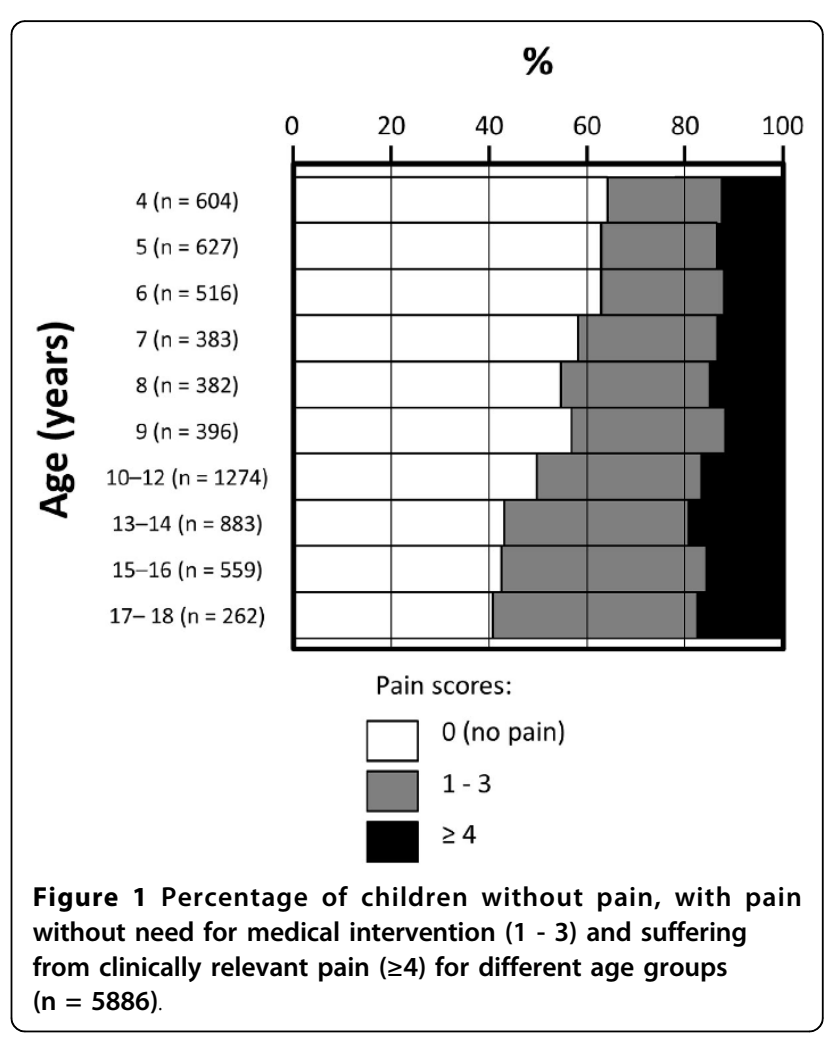




\section{Competing interests}

Authors have no competing interests to declare.

Trial registration: ClinicalTrials.gov Identifier: NCT02083835

\section{Authors' details}

'Department of Anesthesiology and Intensive Care, Jena University Hospital, Jena - Lobeda, Germany. ${ }^{2}$ Institute for Medical Informatics, Statistics and

Documentation, Medical University of Graz, Austria.

Published: 30 October 2015

\section{Reference}

1. Hicks CL, von Baeyer CL, Spafford PA, van Korlaar I, Goodenough B: The Faces Pain Scale - Revised: toward a common metric in pediatric pain measurement. Pain 2001, 93:173-183.

\section{doi:10.1186/2056-5917-1-S1-A8}

Cite this article as: Weinmann et al:: QUIPSinfant: Pain and possible side effects in postoperative children and adolescents. Safety in Health 2015 1(Suppl 1):A8.

\section{Submit your next manuscript to BioMed Central} and take full advantage of:

- Convenient online submission

- Thorough peer review

- No space constraints or color figure charges

- Immediate publication on acceptance

- Inclusion in PubMed, CAS, Scopus and Google Scholar

- Research which is freely available for redistribution 